Baltic Astronomy, vol. 5, 579-588, 1996.

\title{
COMPONENTS OF PHOTOMETRIC INSTRUMENTATION
}

R. Kalytis ${ }^{1}$, R. Skipitis ${ }^{1}$, V. Luja ${ }^{1}$, D. Ališauskas ${ }^{1}$ and E. G. Meištas ${ }^{2}$

1 Institute of Material Research and Applied Science, Astronomical Observatory, Vilnius University, Ciurlionio 29, Vilnius 2009, Lithuania,

2 Institute of Theoretical Physics and Astronomy, Goštauto 12, Vilnius 2600, Lithuania.

Received March 20, 1996.

Abstract. Some components of the photometric equipment, designed and made for the high speed multichannel stellar photometry for the Whole Earth Telescope (WET) program and other astronomical programs, are described. Despite of a special destination, the described equipment could be also used for any kind of stellar photometry, especially for observations of variable stars. Small size and weight of the equipment makes it suitable for observations in expeditional conditions. An original solution of the step-motor feeding for the the filter wheel rotation is presented, and the filter setting system FD 306 based on it is described and discussed.

Key words: instrumentation: photometers

\section{INTRODUCTION}

The Laboratory of Astrophotometry in the Astronomical Observatory of the Vilnius University has some experience in design and manufacture of astrophotometers and their parts. This experience was acquired carrying out the orders of the military and aerospatial companies and astronomical institutions of the former Soviet Union.

During the last four years the Laboratory of Astrophotometry has been engaged in design and modernization of the photometric instrumentation for an international astronomical program - the 
Table 1. List of photometric equipment

\begin{tabular}{|c|c|c|c|c|}
\hline $\begin{array}{l}\text { Device } \\
\text { type }\end{array}$ & Mode & $\begin{array}{l}\text { Purpose } \\
\text { of design }\end{array}$ & Main specification & References \\
\hline $\begin{array}{l}\text { High voltage } \\
\text { dividers }\end{array}$ & $\begin{array}{l}\text { D } 303 \\
\text { D } 304\end{array}$ & $\begin{array}{l}\text { WET } \\
\text { WET }\end{array}$ & $\begin{array}{l}\text { Both for PMT } \\
\text { R } 647-04, \\
\text { grounded minus }\end{array}$ & $\begin{array}{l}\text { Kalytis, Meištas (1995) } \\
\text { Kalytis, Meištas (1995) }\end{array}$ \\
\hline $\begin{array}{l}\text { Amplifier } \\
\text { discrimi- } \\
\text { nators }\end{array}$ & $\begin{array}{l}\text { F } 310 \\
\text { F } 316 \\
\text { F } 318 \\
\text { F } 320\end{array}$ & $\begin{array}{l}\text { WET } \\
\text { WET } \\
\text { WET } \\
\text { General }\end{array}$ & $\begin{array}{l}\text { PPR } 8 \mathrm{~ns}, 100 \mu \mathrm{V} \\
\text { PPR } 22 \mathrm{~ns}, 130 \mu \mathrm{V} \\
\text { PPR } 8 \mathrm{~ns}, 150 \mu \mathrm{V} \\
\text { PPR } 6 \mathrm{~ns}, 150 \mu \mathrm{V}\end{array}$ & $\begin{array}{l}\text { Kalytis et al. (1993) } \\
\text { Kalytis, Meištas (1995) } \\
\text { This paper } \\
\text { This paper }\end{array}$ \\
\hline $\begin{array}{l}\text { Filter } \\
\text { setting } \\
\text { systems }\end{array}$ & FD 301 & WET & $\begin{array}{l}\text { Dual wheel, } \\
5 \text { filters } \\
\text { One wheel, } \\
5 \text { filters }\end{array}$ & $\begin{array}{l}\text { Kalytis et al. (1993) } \\
\text { This paper }\end{array}$ \\
\hline $\begin{array}{l}\text { Power } \\
\text { supplies }\end{array}$ & $\begin{array}{l}\text { A } 304 \\
\text { A 305 }\end{array}$ & $\begin{array}{l}\text { WET } \\
\text { General }\end{array}$ & $\begin{array}{l}\mathrm{HV}, \pm 5 \mathrm{~V}, \pm 12 \mathrm{~V} \\
\mathrm{HV},+5 \mathrm{~V}, \pm 12 \mathrm{~V}, \\
4 \mathrm{~V} \text { for cooler }\end{array}$ & $\begin{array}{l}\text { Kalytis et al. (1993) } \\
\text { This paper }\end{array}$ \\
\hline $\begin{array}{l}\text { Photo- } \\
\text { electric } \\
\text { head }\end{array}$ & FG 304 & General & $\begin{array}{l}250-1100 \mathrm{~nm}, \\
10^{-15}-10^{-9} \mathrm{~W} \\
\text { Weight } 1.85 \mathrm{~kg}\end{array}$ & This paper \\
\hline
\end{tabular}

Whole Earth Telescope (WET) (Nather et al. 1990). Some components of the photometric equipment for the Pancake portable photometer (Meištas 1993) and other astrophotometers were designed and made during this work (Kalytis et al. 1993, Kalytis \& Meištas, 1995). They include the light detecting units named "photoelectric heads" containing photomultiplier (PMT) housings, cooling systems, PMT's, high voltage (HV) dividers, amplifier-discriminators (A-Ds) and power supplies (Table 1).

The listed photometric equipment was designed for the specific WET or other needs. However, this equipment is suitable for a wider astronomical application, especially, for observations of variable stars. Such components as A-D's, filter setting systems, power supplies and others can be used in all types of astrophotometers. Some astronomers can be interested in almost all the mentioned compact parts of the photometric equipment. Such an equipment is comfortable to use in the expeditional work in remote sites. 


\section{SUMMARY OF THE NEW PHOTOMETRIC EQUIPMENT}

\subsection{Amplifier-discriminators F 918 and F 920}

F 318 is the A-D, especially designed for the "one cable" system (Kalytis \& Meištas 1995), i.e. for the photometers in which the signal and the HV power supply are leaded through the same cable (Fig. 1). The F 318 is designed for use with the HV divider D 304 (Kalytis \& Meištas, 1995) in pair. The A-D F 318 differs from the "classic" one by the necessity to use the HV filter at the input of A-D and by absence of the amplifier-booster at the output. The main merit of such construction is a possibility to place the A-D inside the block of electronics, close to the power supplier and the interface. Also, decrease of the number of cables from three to one is a significant gain.

The amplifier-discriminator F 320 of the series F 300 (Kalytis et al. 1993, Kalytis \& Meištas 1995) originally was designed for the WET. However, due to its high speed and sensitivity it is useful for other applications. The principal difference of the F 320 from the main WET A-D F 316 is the absence of the positive feed-back loop in the circuit of the discriminator. It allows to achieve a broad frequency band, but forces to lose a little in sensitivity and in "beauty" of output pulses, i.e. the uniformity of their duration.

\subsection{The filter setting system FD 306}

\subsubsection{Introduction}

It is fashionable now to use the step motors for rotation of filter wheels in astrophotometers. Really, step motors have a property which is very useful for this application. It is the ability of the exact (with the accuracy of one step or better) positioning and electromagnetic (without any mechanical frictional parts) fixation. It seems that it would be enough to apply this property in the standard way, i.e. by feeding the motor with the needed sequence of electric pulses. However, our experience in the design of various systems of filter rotation showed that this way of application of step motors is not optimum and requires some changes. 


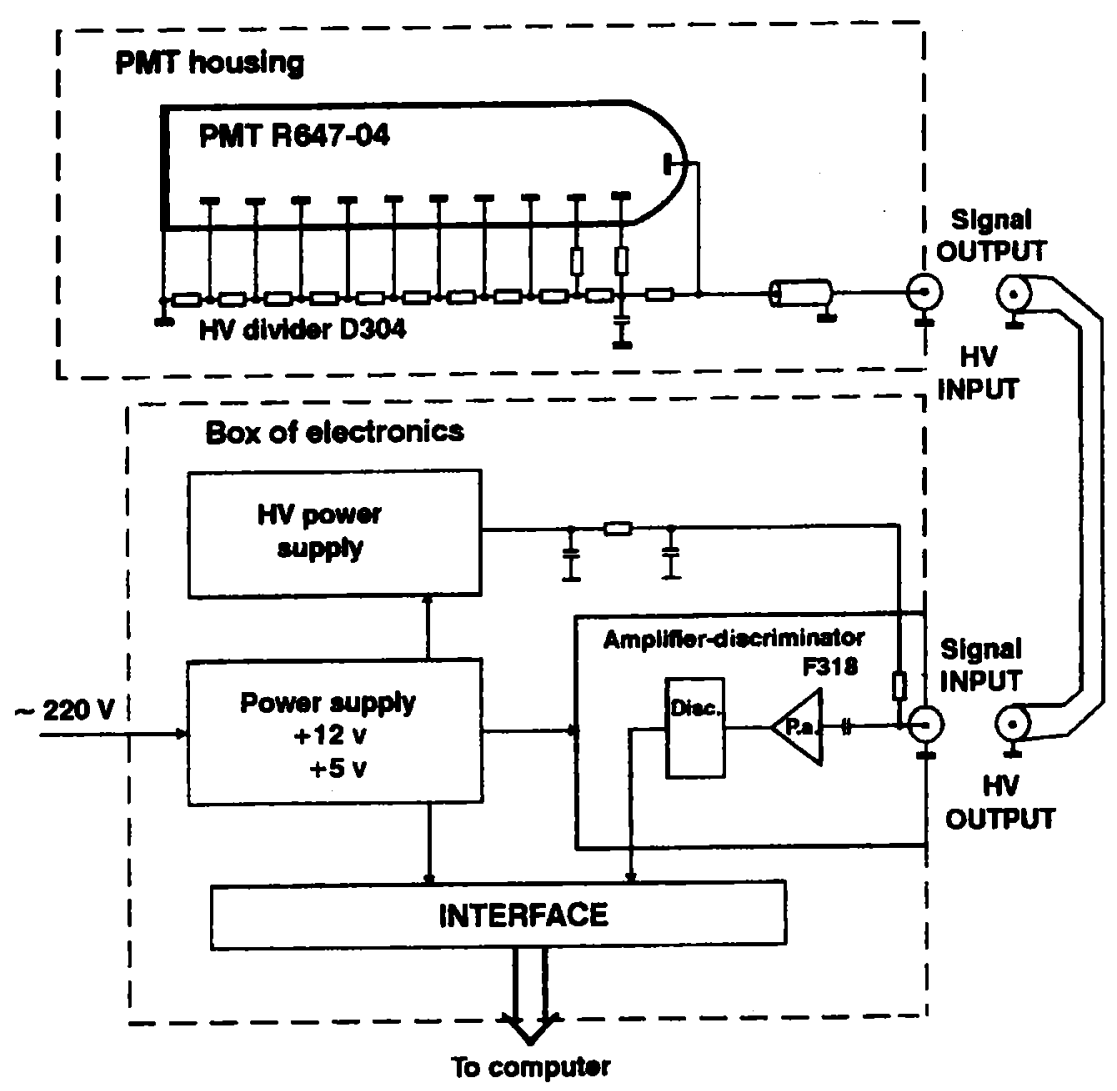

Fig. 1. Block diagram of the "one cable" system

2.2.2. The problems of using step motors for filter wheel rotation

First of all, the moment of inertia of the filter wheel in astrophotometers is larger than that of the motor rotor. Consequently, the step motor either works in the forced mode or one should use a more powerful motor. Its power is needed to extinct the mechanical oscillations which appear after each step. For damping the oscillations and for the optimum working mode of step motors, the sophisticated synchronizing systems can be used. Full feed-back after each step in such systems allows to switch on the pulse for the second step in a moment which is the most favourable in the sense of own oscillations of the system 'step motor plus filter wheel'. In some cases this way 
allows to design the systems which use the inertia moments of the step motor and filter wheel in the optimum mode and allows to reach maximum rate of rotation, i.e. to design the system close to an ideal one. However, such systems are very complicated and need, as a rule, the control by a microcontroler or a computer. Furthermore, even in these systems it is difficult to avoid the oscillations which arise after the motor stops.

The described problems arise and are similar both in the unipolar and bipolar motor types, when step motors are controlled by electric pulses.

\subsubsection{What is the solution?}

We decided to exploit a specific way of operation of step motors in astrophotometers. For setting the necessary filter, the motor makes turns of the wheel from time to time, in comparatively large angles. For doing this, the motor usually makes tens of steps. Positioning of the wheel may be not very exact, since in most cases filter sizes are significantly larger than their shifts per step (if the motors with hundreds of steps are used).

Almost completely opposite requirements are held for the step motors used in the devices for information storage and printing. Turns of the motors in these systems are of variable size and direction, and the parts to be moved (magnetic or printing heads) are comparatively lightweight.

Bearing in mind all the mentioned above, we decided not to stop the motor after each step, i.e. the wheel rotates continuously from one position to other. In this case only one start and one stop perturbations will happen during a cycle.

By the way, if we connect to the input of an oscilloscope one of the windings of the step motor and move the rotor continuously, we see on the screen... a sinusoid, not the pulses which usually feed the pulse motors. Thus, the "native" voltage for the pulse motor power supply is the sine voltage, as for a usual synchronous electric motor.

Therefore, if we supply the sine voltage of the corresponding phase to the windings of the step motor, its rotor rotates evenly, without steps. However, the main property of the step motor, its "stepness", is preserved. Each step is being fixed electromagneticaly.

Only the problems related with start and stop of the motor in the needed positions should be solved in this case. This can be made 
by counting the number of periods, i.e. using the traditional way of position determining.

\subsubsection{How does it work?}

We have chosen the way of the full feed-back in each filter position. The control of such system becomes very simple in this case. If the feed-back indicates that the necessary position is not yet reached (in our case, the special code is not found), the step motor rotates uniformly, supplied by the sine voltage. When the required position is reached (or when the feed-back finds the code set), the stop circuit is switched on and the wheel is stopped. Some oscillations of the wheel can take place. A more reliable stopping can be reached if the power accumulated in the capacitor is used. Very weak power is needed for fixing the wheel after damping the oscillations. When other filter is needed, the code for the feed-back has to be changed. The rotor starts to rotate evenly searching a position with this code. When it is found, the wheel stops again.

The use of the full feed-back for the fixed positions allows to minimize the use of the computer or microprocessor resources. In this case, the computer sends only the code of the filter wanted; after that the system operates autonomously. Moreover, we can use the information that the necessary position of the filter wheel is found and the measuring can be started.

The information on the necessary position reached can be obtained in other way, by taking into account the rate of rotation, which is known precisely and depends on the frequency of the sine voltage used. We use a frequency of $50 \mathrm{~Hz}$ and the motors of 200 steps, as a rule. Thus, the full revolution of the rotor takes $1 \mathrm{~s}$. If we have five filters on the wheel, the next filter will be set in $0.2 \mathrm{~s}$. If ten filters are used, this time is $0.1 \mathrm{~s}$.

It seems that the use of a higher frequency, $100 \mathrm{~Hz}$ for example, allows to accelerate the wheel rotation. However, our tests showed that a frequency of $50 \mathrm{~Hz}$ (or $60 \mathrm{~Hz}$ ) is optimum for the step motors of $1-2 \mathrm{~W}$ power and for the filter wheels of usual diameter used in astrophotometers. The higher frequency is inexpedient due to the inertial moment of the system 'step motor plus filter wheel'. 


\subsubsection{The features of FD 306}

We have designed and produced the filter wheel rotation (filter setting) system which uses the main merits of step motors and avoids their imperfections which happen using them in astrophotometers. Really, our filter setting system.FD 306 has some better qualities in comparison with the traditional systems using step motors.

These merits are the following:

(1) faster rotation of the wheel,

(2) uniform (soft) turn to the needed position; it means higher reliability of the system due to a lower probability for the filters to get loose due to shaking,

(3) significantly lower power consumption,

(4) lower exhaustion of the computer resources for the control and its simplicity,

(5) full feed-back in each filter position, which ensures a setting of the wheel in the needed position and a possibility to receive information that this position is reached.

2.2.6. The circuit diagram of FD 306

The circuit diagram of one-wheel filter setting system FD 306 is presented in Fig. 2. This system is a further modification of the analogous system FD 301 (Kalytis et al. 1993), i.e., it uses the same principles of the filter wheel rotation and its control. However, some considerable improvements of its operation have been made, such as optimization of the circuit including more reliable execution of start and stop and minimization of the power consumption. The analogous-type comparator is replaced by the digital one. Also, the filter wheel can rotate in both directions now.

The system can be controlled by the WET data acquisition program Quilt 9 via interface designed by Clemens (1993), but a special EPROM program is written for this case because of completely different principles of filter wheel rotation and its control. However, the system can be controlled through any kind of interface, together with a computer using a parallel code. 
R. Kalytis, R. Skipitis, V. Luja et al.

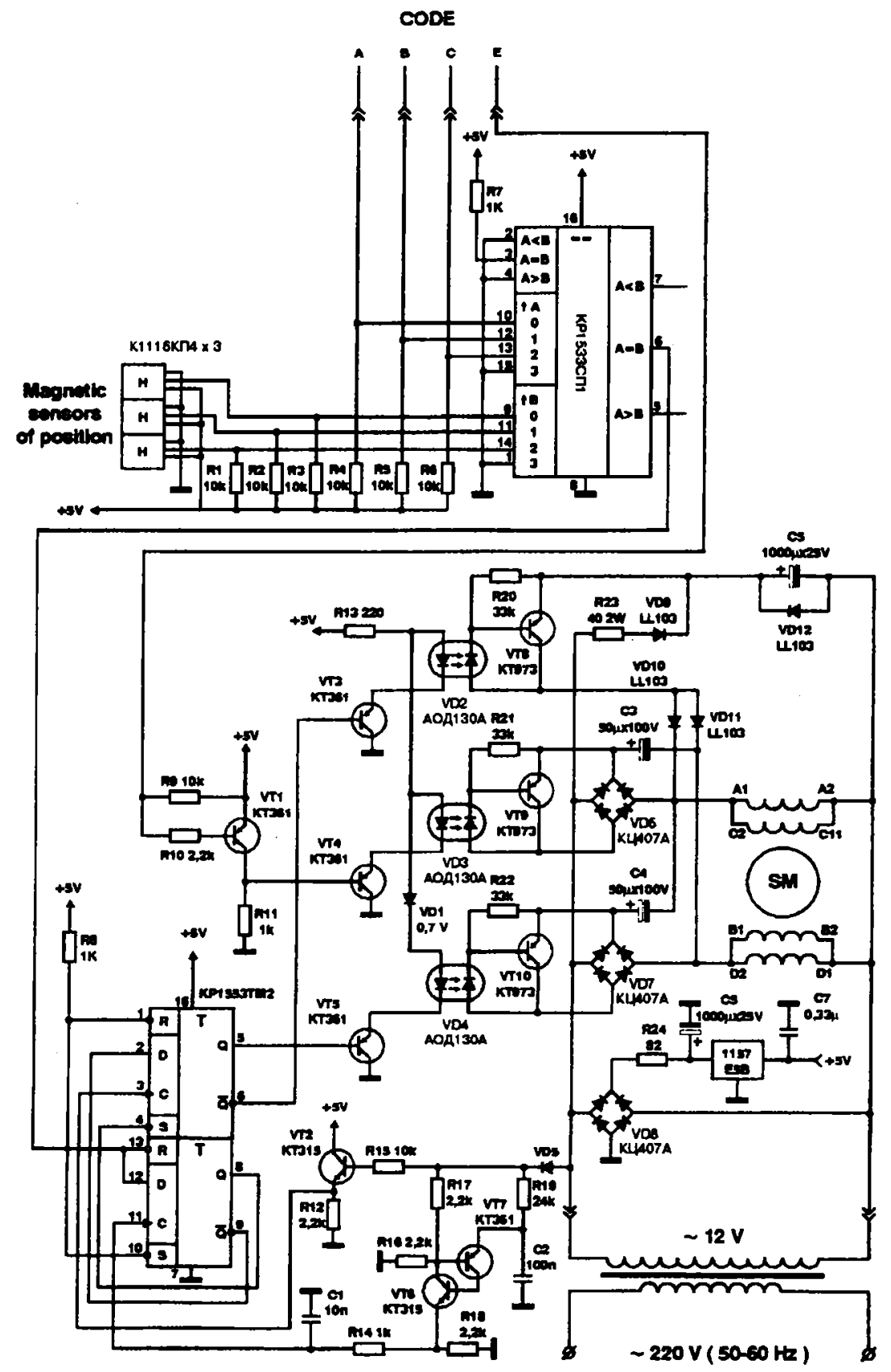

Fig. 2. Circuit diagram of the filter setting system FD 306 
Table 2. Main specifications of the photoelectric head FG 304

\begin{tabular}{ll}
\hline $\begin{array}{l}\text { Spectral range } \\
\text { Dynamic range } \\
\text { at } \lambda=1.06 \mu \mathrm{m})\end{array}$ & $(0.25-1.1) \mu \mathrm{m}$ \\
$\begin{array}{l}\text { Maximum error of mesurements } \\
\text { (when } 1.1 \times 10^{4} \text { signal pulses }\end{array}$ & $\left(10^{-15}-10^{-9}\right) \mathrm{W}$ \\
$\begin{array}{l}\text { are stored) } \\
\begin{array}{l}\text { Sensitivity variations } \\
\text { Dead time }\end{array}\end{array}$ & $\begin{array}{l}\text { less than } 5 \% \text { per } 10 \text { hours } \\
(20 \pm 2) \mathrm{ns}\end{array}$ \\
$\begin{array}{l}\text { Output pulses } \\
\text { Temperature of the PMT }\end{array}$ & $\begin{array}{l}\text { correspond to fast TTL } \\
\text { fve stabilized temperatures } \\
\text { which can be set in the range } \\
\text { of }-55^{\circ} \mathrm{C} \text { to }-35^{\circ} \mathrm{C} \text { depending } \\
\text { on the surrounding } T \\
\text { using two-stage thermoelectric }\end{array}$ \\
& $\begin{array}{l}\text { cooler with actively ventilated } \\
\text { heat absorber }\end{array}$ \\
$\begin{array}{l}\text { System of the PMT cooling } \\
\text { Power requirements }\end{array}$ & $\sim 220 \mathrm{~V}, 0.18 \mathrm{~A}$ \\
$\begin{array}{l}\text { Dimensions: } \\
\text { of detector unit } \\
\text { of power supply unit A } 305\end{array}$ & $\begin{array}{l}(180 \times 110 \times 110) \mathrm{mm} \\
\text { Weight: }\end{array}$ \\
$\begin{array}{l}\text { of the detector unit } \\
\text { of the power supply unit A } 305\end{array}$ & $\begin{array}{l}1.85 \mathrm{~kg} \\
0.90 \mathrm{~kg}\end{array}$ \\
\hline \hline
\end{tabular}

\subsection{The photoelectric head FG 304}

A short description of the photoelectric head FG 304 as an illustration of the successful application of the equipment described, is presented below.

The FG 304 head was designed and made as a light detecting part of the special stellar photometer. This photometer was planned to use for investigation of the meteorological parameters of the atmosphere by observing the stars, spectrophotometric standards. This way of atmosphere exploration is important in the polar regions, where the night lasts a half of a year. The photometer is of small size and weight.

Unfortunately, the necessity to make measurements in a wide spectral range forced us to use the PMT with the S1 photocathode 
with low quantum efficiency. Attempts to replace this type of PMT by one having the InGaAs photocathode are undertaken now.

A distinctive design of the heat absorber of the thermoelectric cooler has solved the problem of its effectiveness and weight. We have avoided a necessity to use the water for a heat transfer.

Properties of FG 304:

- wide spectral range,

- wide dynamic range,

- high precision of light registration,

- small size and weight,

- ability to operate in the astronomical conditions (no need of running water for the cooling system).

\section{REFERENCES}

Clemens J. C. 1993 , Baltic Astronomy, 2, 501

Kalytis R., Skipitis R., Karaliūnas A., Dzindzelèta B. 1993, Baltic Astronomy, 2, 504

Kalytis R., Meištas E. 1995, Baltic Astronomy, 4, 497

Meištas E. 1993, Baltic Astronomy, 2, 498

Nather R.E., Winget D. E., Clemens J. C., Hansen C. J., Hine B. P. 1990, ApJ, 361, 309 